\title{
Some Eastern Europe experiences with environmental aspects of urban plans
}

\author{
B. Vrbaski ${ }^{1} \&$ S. Krnjetin ${ }^{2}$ \\ ${ }^{1}$ Urban Planning, Development and Research Centre, Novi Sad, Serbia \\ ${ }^{2}$ Faculty of Technical Science, University of Novi Sad, Serbia
}

\begin{abstract}
The preparation of Strategic Environmental Assessment, as an important step in the chain of hierarchical solving of environmental problems, represents a very important factor in shaping our surroundings. The increasing pollution of all environmental elements emphasizes the need to react at all levels, in particular by strategic planning when built up environments are formed. The aim of this paper is to analyze our experience in application of the Law on Strategic Environmental Impact Assessment. We have paid special attention to its drawbacks, observed in preparation of a strategic environmental impact assessment. Strategic environmental assessments have mostly been prepared in a "bureaucratic" way without employing adequate methods and foremost without the corresponding input data, which would be processed by means of adequate methods. For the purpose of relevant document preparation as efficiently as possible, 13 typical examples have been analyzed and a series of principles, criteria and solutions for observed problems is defined on the basis thereof.
\end{abstract}

Keywords: environmental indicators, public participation, strategic environmental impact assessment.

\section{Introduction}

As one of many countries in transition, Serbia is also been faced with existing problems related to protection of the environment. Significant changes in the legislation of the Republic of Serbia in the area of environment protection which occurred in the course of 2004 when four new laws were adopted (the Law on Environment Protection [1], the Law on Integrated Prevention and Control of Environmental Pollution [2], the Law on Environmental Impact Assessment [3] 
and the Law on Strategic Environmental Impact Assessment [4]) have given rise to realistic needs related to the compliance of practice with new legal regulations in this area. Since the applicable Law on Strategic Environmental Impact Assessment defines methodology framework for the preparation thereof, there is a general conclusion that this legally defined methodology should be used as an initial framework and there is no methodological "recipe" for the preparation of strategic environmental impact assessments. This approach has been accepted not only by the world's experts dealing with this issue, e.g. Sadler and Verheem [5], Therivel and Partidario [6] and others, but also by domestic experts such as Stojanović and Spasić [7] and others. This is primarily due to the fact that strategic environmental assessments are made for plans and programmes of varying levels and scopes, for diverse purposes of space and because they involve a complex system of participants and data which they deal with. Therefore, it is more useful to develop in practice a set of principles which will be applied within legally defined stages of preparation and deploy proposed problem solutions which have been noticed in practice so far. Well known methods, which have been used so far more in the world than in our country, as for example, identification methods, expertise, control lists and questionnaires, matrices, multi criteria analysis, SWOT analysis [8], ecological capacity analysis and the like, are recommendable in each of corresponding cases for certain stages of strategic assessment which are defined in the Law on Strategic Environmental Impact Assessment.

Strategic environmental assessments have mostly been prepared in a "bureaucratic" way without employing adequate methods and foremost without corresponding input data which would be processed by means of above methods. For the purpose of relevant documents preparation as efficiently as possible, 13 typical examples have been analyzed and a series of principles, criteria, premises and solutions for observed problems is defined on the basis thereof.

\section{Presentation of some basic premises}

\subsection{Premise 1}

The social aspects of environmental impact assessment of plans are rarely elaborated on.

In that respect, the strategic environmental assessments rarely address the following issues: freedom of movement of disabled persons, accessibility of areas for children and old people, health of the population and the like. For the purpose of resolving these issues, it is desirable to apply participation planning which ensures that all relevant interventions be based on needs and observed problems of users, local capacities and lessons learned in previous experiences. The participation process implies that all relevant participants work together in order to develop a mutual goal and that they all participate in the decision making process [9]. 


\subsection{Premise 2}

A cumulative environmental impact assessment represents a significant contribution in the preparation of documents.

The synergy of possible impacts often gives a new picture about the state of the environment and thus, necessary interventions for its protection. In that respect, it is necessary to provide full cooperation of all relevant experts in the team in order to generate resultants of diversified impacts.

\subsection{Premise 3}

The lack of measures envisaged in the case of a disaster is an important deficiency of relevant documents.

The lack of measures in the case of disasters in the majority of prepared documentation means direct devastation of the environment in the case of an incident. This often causes not only increased work on environmental recovery but also an inability to recover and return to the previous state. For the purpose of defining these measures, teamwork is essential in preparing strategic environmental assessments, as well as consultations with professionals in the areas in which incidents may occur.

\subsection{Premise 4}

Although all legal obligations have been very often adhered to with respect to the contents of strategic environmental assessments, pertinent areas are not dealt with in an adequate way.

In most of the cases, the table of contents includes all items stipulated by the law but they are often "routinely" treated and identical text can be found in almost all examples elaborated by one professional organization. The routine treatment of strategic environmental assessments makes them lose their meaning since valid environmental impact cannot be found in documents prepared in the above manner. This primarily refers to chapters dealing with environmental indicators, the assessment of possible impacts with the description of protective measures, guidelines for the preparation of strategic environmental assessments at lower hieratical levels, presentation and evaluation of alternative solutions and methodology used. Nevertheless, the analysis of concrete examples made by the same organization shows that in time certain elements of strategic environmental assessments are evaluated thus providing a more comprehensive overview of important impacts.

\subsection{Premise 5}

The concept of strategic environmental assessments depending on the type and scope of the plan for which environmental impact is elaborated is rarely changed.

Very often, the same methodology is used in preparing spatial plans and in zoning ordinances, as well as in spatial plans for special purposes (for example, natural reservations) and industrial zones as a direct consequence of the routine 
making of these documents. For the purpose of providing high quality solutions, applied methods should be varied with reference to the type of and scope of plans. At the same time, it should not be confined only on the use of the present situation qualitative analysis [10].

\subsection{Premise 6}

All aspects of environmental impact should be elaborated adequately.

The emphasis should not be on the narrow professional field of the maker of the strategic environmental assessment. In that respect, teamwork is very important, that is to say, experts and professional organizations should be involved in the preparation process. It cannot be expected from a person assigned with the task to "cover" all areas characteristic for a given plan however, the first and a very important step is to "recognize" this fact and include other colleagues in resolving distinctive issues. This, however, does not imply a simple protocolar opinion request from professional organizations and competent public companies but active joint works in considering and resolving issues by deploying various techniques and methods typical for a given area and/or profession. The task of a person assigned to prepare a strategic environmental assessment is not to do something alone but to evaluate the composition of a project team, coordinate the team's work and finally put received information into a unique document. Even at the very level of an organization making a document, it is frequently noticeable that there is an imbalance in the team members' coordination which can be illustrated by a simple example that a person assigned to prepare strategic environmental assessment receives from persons in charge of plan preparations ready made solutions without a possibility to change anything in a large number of cases. This in the very start excludes any sort of alternative analysis of solutions as they do not exist at all. In order to enable cooperation between all members of the team, the Law stipulates parallel preparation of plans and strategic environmental assessments.

\subsection{Premise 7}

Strategic environmental assessments usually include and present a small number of input data.

The analysis of chosen examples has shown that only in a limited number of cases, often prepared by professional organizations from the territory of Belgrade, corresponding measurements have been made and/or certain number of data obtained by these measurements has been analyzed. It is a well known fact that in many towns in our country, systematic measurements, which could be used as indicators of environmental conditions, have not been made so far. Also, the preparation of majority strategic environmental assessments does not even involve targeted and/or one-time measurements lasting for one to three days. The analysis often takes into account average parameters from measurement points, which are at a distance of as much as up to 50 kilometres from investigated areas. Although one-time measurements by no means present a complete picture of environmental conditions since they represent a momentary 
situation in a relevant season at certain atmospheric influences and the like, they are very important because they often provide valid data of, for example, the quality of soil and water. Data gathered in the above manner provide solid grounds for further work. Often, financial costs are underlined relevant to the collection of necessary data, but this problem can be resolved by inclusion of costs in the overall price specified for rendering strategic environmental assessments to be borne by the investor. The placement of seven automatic stations for monitoring the quality of ambient air in Vojvodina can be emphasized as an excellent example of global cooperation between the Provincial Secretariat for Environment Protection and Sustainable Growth and the European Environment Information and Observation Network. Data obtained from automatic stations will be primarily used for the assessment of the population's exposure and health impact evaluation, then as the basis for strategic planning and work of inspection services, as well as for predicting and estimating trends in air quality assessments. Configuration of each station is designed in such a way to monitor pollution which is characteristic for the site at which it is located and two stations are placed within protected natural resources zones and they serve as referent, i.e., base stations [11].

\subsection{Premise 8}

An insufficient number of inadequate indicators are very often chosen.

As a consequence of scarce collected data, there is a choice of an inadequate number and type of environmental indicators [12]. Thus, for example, human health, as one of the most important environmental parameters, is very rarely taken into account within strategic environmental assessments. However, it can be concluded that this practice has changed in time and by deploying new methodologies in the preparation of strategic environmental assessments, many adequate indicators are introduced [13].

\subsection{Premise 9}

Plans with different hierarchical levels, i.e., strategic environmental assessments thereof, are very often prepared identically.

The above statement is always accompanied by the question whether in situations when the preparation of municipal spatial plans coincides with the preparation of towns' master plans, strategic environmental assessment should be made for each of the plans separately or one strategic environmental assessment could refer to both plans. The concrete answer to this question has not yet been given. With reference to this question, two approaches can be distinguished. The first approach assumes that strategic environmental assessments, particularly those of a higher rank, should not overly elaborate impacts of concrete companies which present environmental hazards with their activities. The other approach is that irrespective of their level strategic environmental assessments should collect as many data as possible about potential environmental hazards. After the analysis of selected examples, it can be concluded that strategic environmental assessments containing detailed 


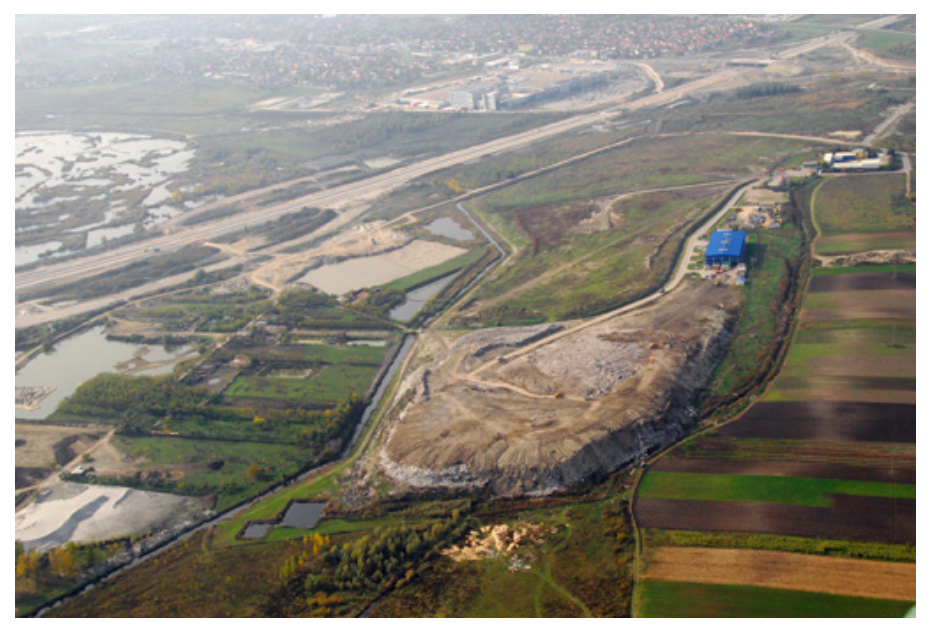

Figure 1: Built residential settlement in close neighbourhood of a city dump in Novi Sad.

analyses of every potential environmental hazard are much clearer and more valuable as they specify the real purpose of these documents. They show actual picture at the terrain and fully justify objectives of strategic environmental assessments which have been set in advance. Concrete data are available in these documents and there are no many circumlocutions or opportunities left for wrong assessments.

\subsection{Premise 10}

In the majority of cases, public participation is not adequately implemented.

Public participation can be accomplished through various interest groups such as: the local population, professional public, business sectors, nongovernmental organizations and administrative authorities [14]. Based on the analysis of selected examples, it can be concluded that in the majority of cases there were no or less than five remarks within public inspection of strategic environmental assessments. Most often, the reason for that is the local population's failure to get informed, and/or insufficient knowledge of citizens about possibilities to lodge complaints during public inspection. This situation is characteristic not only when strategic environmental assessments are concerned but also in the procedures of public inspection of planning documentation. Resolving this problem is possible in cooperation with neighbourhood communities which could raise awareness and interest for relevant topics of their citizens by means of written notifications. These concrete written notifications should, in addition to basic data about public investigation, provide explanations of citizens' rights in simple "popular" language which will even more contribute to their education. This type of communication is not impossible since a citizen gets informed about many other events in this way. Business sectors are frequently informed of the 


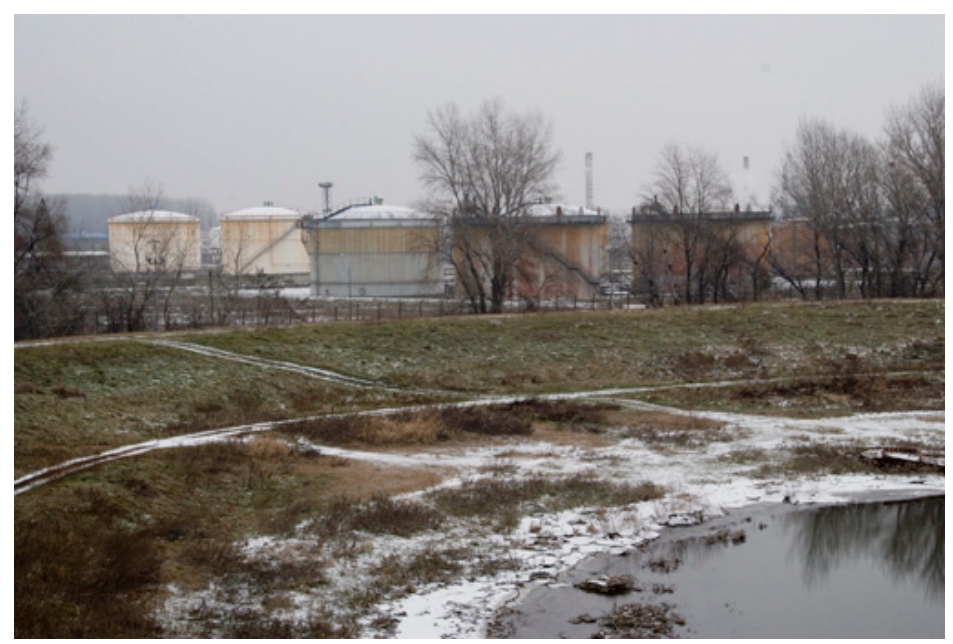

Figure 2: Large manufacturing complex for nitrogen pesticides as a long standing threat in Novi Sad.

procedure of public investigation and most often their complaints involve denial of information gathered by the elaborator in relation to the harmful effects of facilities owned by them.

\subsection{Premise 11}

Project implementation on the public land is often uncertain.

Taking into consideration the fact that the majority of "positive" interventions which are anticipated in strategic environmental assessments refer to public surfaces, a very small portion of practical realization of these projects imposes an important problem. A typical example of this problem concerns protective belts along various infrastructural corridors. The resolution of this problem is possible by putting a condition to implement protective corridors together with infrastructural directions. Unfortunately, in our country, this problem has been made banal by means of a traffic route's rank decrease through various "documents", for example, in the case of a highway in order to enable the construction of commercial and residential buildings along its way, instead of a protective belt. Thus we have a paradox and instead of the protective belt we "arrange" commercial and residential buildings and in so doing breach basic principles of sustainable growth.

\subsection{Premise 12}

Irrespective of the cross border impact analysis, when strategic environmental assessments are made, legal provision defining spatial scope of a plan is often interpreted in a strictly "legalistic" way. 
As a consequence, in some of the examples, serious environmental hazards are not taken into account although they are in close proximity of an area for which this document has been prepared. An example for that is the exclusion of the pharmaceutical factory "Galenika" from the strategic environmental assessment made for illegally constructed residential settlement in its close neighbourhood. Thus, in the same document, we talk about cross border impacts on the one hand and neglect environmental hazards which are very close to the processed area on the other hand.

\subsection{Premise 13}

The control of the situation at the terrain carried out by the Inspection represents the weakest link in the overall procedure of spatial planning.

Fines which should be paid by polluters are very often insufficiently nonencouraging and legal proceedings against polluters are in many cases ruled in favour of polluters by their experienced legal representatives. This is the reason why we have a lot of problems nowadays such as wild dumps, inadequate control of equipment built in large manufacturing complexes and lack of control in the use of pesticides. In line with above stated, according to the Law on Environment Protection, crucial changes in the plant's operations are assessed by competent authorities which very rarely occurs in practice as the term "crucial" changes is very vague. The same Law stipulates the obligation of owners of existing plants which potentially jeopardize the environment to obtain corresponding integrated permits until 2015. In the period of next six years, the same companies will considerably endanger the environment and this will in turn aggravate its recovery to a large extent. Even in cases when the plan anticipates the plant's demolition or reconstruction, integrated permits will not be obtained if the investor does not instigate the procedure. The fact that a single integrated permit has not been issued so far both at the territory of Vojvodina and at the territory of the whole country indicates that the implementation of elements from strategic environmental assessment proceeds very slowly. Transitional provisions of the Law on Integrated Prevention and Control of Environmental Pollution stipulate that the Government of the Republic of Serbia will enact the Programme for Compliance of Certain Economic Branches with this Law, which has not been done so far. Therefore, there are no corresponding applications for issuing permits for existing plants. Undoubtedly, all legal measures will affect the environment but their effects will be substantially delayed, mostly due to the complexity of procedures associated with obtaining necessary documentation and the lack of dialog among services in charge of their enforcement.

\subsection{Premise 14}

There are no systemic solutions for environmental problems.

Due to the obvious lack of systemic solutions, serous environmental problems occur and they cannot be resolved simply by means of a corresponding strategic environmental assessment. This is, for example, in the case of disposal and treatment of toxic wastes which have not been resolved in our country yet. An 
example concerning the construction of illegal buildings under the existing and planned long distance power lines is very important since some of the Town's decisions prevent their legalization whereas actual impact of these infrastructural directions on the population living there has not been assessed anywhere. This problem can hardly be resolved by means of strategic environmental assessment as initiatives and actions are required at all levels starting from the Government [15].

\section{Conclusion}

Research in this field represents only the basis for further work. Therefore, defining concrete problems and opportunities for their solving represent an important factor of the whole process. We all take part in this process, from decision makers, experts, and interested public to every individual who will live in this environment. The analysis of new examples of strategic environmental assessments, dialog among persons involved in the preparation of these documents, monitoring implementation, as well as adequate public participation, represent the most important contribution to problem solving. We are faced with a difficult task and address it with limited resources which make the challenge even bigger.

\section{Reference}

[1] Law on Environment Protection, Official Gazette of Republic Serbia No.135, 2004.

[2] Law on Integrated Prevention and Control of Environmental Pollution, Official Gazette of Republic Serbia No.135, 2004.

[3] Law on Environmental Impact Assessment, Official Gazette of Republic Serbia No.135, 2004.

[4] Law on Strategic Environmental Impact Assessment, Official Gazette of Republic Serbia No.135, 2004.

[5] Sadler, B., Verheem, R., Strategic Environmental Assessment - status, challenges and future actions. The Hague. Ministry of Housing, Spatial Planning and Environment of the Netherlands, 1996.

[6] Therivel, R., Partidario, M.R., The practise of Strategic Environmental Assessment, London: Earthscan, 1996.

[7] Stojanovic, B., Spasic, N., Application of EIA/SEA system in land use planning - Experience from Serbia, A Global Conference on Strategic Environmental Assessment "International experience and perspectives in SEA", Prague, 26.-30.09.2005.

[8] V. Zwaenepoel, L. SWOT Methodology and Regional Development Planning, www.GBN.com

[9] Disability Monitor Initiative South East East Europe, Free Movement of Disabled Persons in Southeast Europe: Inaccessible Right, Belgrade, 2006, page 12 
[10] Environmental Protection Agency Ireland, Development of Strategic Environmental Assessment Methodologies for Plans and Programmes in Ireland (2001-DS-EEP-2/5), 2003.

[11] Provincial Secretariat for Environmental Protection and Sustainable Growth, Network of Automatic Stations for Monitoring the Quality of Ambient Air in Vojvodina, Novi Sad, 2008.

[12] Bell, S., Morse, S. Sustainable indicators: measuring the immeasurable, Earthscan Publications, London, 1999.

[13] United Nations, Indicators of Sustainable Development: Guidelines and Methodology, UN-CSD, 2001.

[14] Healy, P. Collaborative planning, MacMillian press, London, p.121-125, 1997

[15] Vrbaski, B., Krnjetin, S. Experiences of the Republic of Serbia with the preparation of strategic environmental impact assessment of plans, Prostor, Zagreb, (accepted for publishing No.37, June 2009)Provincial Secretariat for Environmental Protection and Sustainable Growth, Network of Automatic Stations for Monitoring the Quality of Ambient Air in Vojvodina, Novi Sad, 2008. 